\title{
LOSS OF CONFINEMENT FOLLOWING A SAWTOOTH INTERNAL DISRUPTION IN PBX TOKAMAK
}

\author{
H. Takahashi. W. Morris ${ }^{1}$, S. Sesnic, K. Bol, R. Fonck, B. Grek, G. Gammel. \\ W. Heidbrink, R. Kaita, S. Kaye, H. Kugel, B. LeBlanc, M. Okabayashi, \\ S. Paul, M. Reusch, and D. Ward \\ Plasma Physics Laboratory, Princeton University \\ Princeton, New Jersey C8544
}

Some bean-shaped plasmas heated by neutral beam injection lose a large amount of energy $\left(\delta \beta_{p \perp} / \beta_{p \perp} \leq 20 \%\right)$ within a short period $(0.3-6 m s)$ following a sawtooth internal disruption. indicating a momentary worsening of the confinement. The mosi severe $\left(\delta \beta_{p \perp} / \beta_{p \perp}>20 \%\right)$ events iead to discharge termination. The internal disruptions in the PBX plasmas often have an unusually large inversion radius, up to $75 \%$ of the plasma half-sidth.

\section{DISCLAIMER}

This report was prepared as an account of work sponsored by an agrncy of the United States Government. Neither the United States Government nor any agency thereof, nor any of their employees, makes any wrranty, express or implied, or assumes any legal liability or responsibijity for the accuracy, completesess, or usefulness of any information, apperatus, product, or process disclosod, or represents that its use would not infringe privately owned rights. Reference hercin to any specific commercial prodtuct, process, or service by trade name, trademark. manufactures, or otberwise does not necessarily constitute or imply its endersement, recommendation, or favoring by the United States Government or any agency thereaf. The view.s and opinions of authors expressed hereig do not necessarily state or reflect those of the Unitod States Government or any agency thereol.

\footnotetext{
${ }^{1}$ Balliol College, University of Oxford, U.K.
} 
In most tokamak discharges, a repetitive process known as sawtooth oscillations ${ }^{1}$ has been observed. each cycle of which is composed of a period of gradual increase in $T_{\text {e }}$ (electron temperat ure) followed by an internal disruption. Mechanisms that lead to the internal disruption have recently received an intense interest. Detailed measurements using advanced diagnostic techniques ${ }^{2.3}$ have become available, and theoretical models. ${ }^{4.5}$ radically different from the widely accepted one. ${ }^{6}$ have been proposed. Sawteeth with a very large change in the electron temperature, ${ }^{3}$ or in the SXR (soft X-radiation) signal' have also been reported. The profile modification due to the sawtooth oscillations has recently been reported ${ }^{6}$ as an important element in determining whether a fusion plasma can be brougint to ignition. The internal distuption expels an amount of energy in the piasma core inside the so-called inversion point into the outer region. The inversion point is believed to lie somewhat beyond the surface where the safety factor, $q$, is unity. The traditional view bolds that the internal disruption causes mostly redistribution of energy wirhin the plasma, rather than the loss from it, and the excess energy given to the outer region diffuses out at a rate commensurate with $\tau_{E G}$ (global energy confinement time). Events following the internal disruption, however, have received scant attention in comparison, in spite of a body of evidence ${ }^{9}$ that the energy and particle transport, not only in the core, but also in the outer region may be adversely affected by the internal disruption.

He report in this article observations (1) that the energy can be promptly lost from the plasma, rather than being simply redistributed within it, (2) that the size and/or the rate of the loss can be great, and (3) that there exist internal disruptions with an unusually large inversion radius. These abservations, made in neutral-beam-injection(NBI)-heated, bean-shaped plasmas in the PBX tokamak, ${ }^{10}$ provide new information for modeling of tokamak discharges with sawieeth ${ }^{\boldsymbol{\theta}}$ and a clue for studies of the sawtooth mechanism. A high resolution diamagnetic loop and compensation loops, all mounted inside the vacuum vessel, are used to determitue the size and rate of change of $\Delta \Phi_{t}$ 'toroidal flux displared by the plasma--diamagnetic' flux). The measurement is free from shielding effect: of the vessel eddy currents and has a fast tirne response needed to follow the internal disruption. Results from the diamagnetic and other magnetic diagnostics are used to determine changes in $\beta_{p \perp}$ (poloidal $\beta$ associated with the perpendicular energy, $W_{\perp}$ ). In order to quantify approximately the rate of additional energy loss due to the sawtooth crash, we define an instantaneous confinement time as $\tau_{E} \equiv W_{\perp} /\left(P-\dot{W}_{\perp}\right)$, where $P$ is the total (injected NBI and ohmic) power, and compare it with $\tau_{E G}$. The $\tau_{E G}$ is the moving average of $\tau_{E}$ determined over a period (1ims) long compared to the period of momentary confinement changs. Following an internal disruption there is a slight rise in the plasma current (mostly $\delta I_{p} / I_{p}<2 \%$ ) and a change in the $S_{1}$ fartor, ${ }^{11}$ both of which contribute to the change in $\beta_{p \perp}$. The rate of change in these quantities is, however, smaller than that of the torojdal flux. Neglecting these contributions and under an assumption that $\tau_{E G} \simeq W_{\perp} / P$ over the averaging period, the ratio of the global 
to moment ary confinement times can be approximated in terms of the rate of change in $\Delta \Phi_{t}$ alone.

$$
\frac{\tau_{E G}}{T_{E}}=1-\frac{r_{E G}}{\hat{\beta}_{\mathrm{p} \perp}} \frac{\Delta \dot{\Phi}_{t}}{\Phi_{p}} .
$$

Here, $\Phi_{p} \equiv\left(\mu_{0} I_{p}\right)^{2} / 8 \pi B_{\infty 0}$ is the paramagnetic flux, where $B_{\phi 0}$ is the toroidal field at the plasma geometrical center. The approximations introduced here generally result in an underestimate of the confinement ratio, especially for slow events. The rat io is however. taken only as an approximate yardstick for the momentary confinement degradation. The evolution of sawteeth is shown in Fig. 1 for a hydrogen discharge heated by $1.9 \mathrm{MIF}$ of $\mathrm{t}$ wo co-perpendicular deuterium beams. Sawteeth are evident on the SXR signal (Fig. 1(c)) beginning at about $390 \mathrm{~ms}$ during the ohmic heating phase and throughout ine $N B \mathrm{Bl}$ heating that begins at $450 \mathrm{~ms}$. No oscillations are discernible on the $\Delta \Phi_{t}$ signal during the ohmic and early NBI phases to the scale shown in Fig. 1(b). Oscillations in $\Delta \Phi_{\mathrm{t}}$. coincident with those in the SXR signal, appear about $60 \mathrm{~ms}$ into the NBI phase. The $I_{p}$ is little affected by the oscillations (Fig. 1(a)). During the early NBI heating phase, in many discharges the internal disruptions cause only a small $\Delta \Phi_{t}$ drop (corresponding typically to $\delta \beta_{p \perp} / \beta_{p \perp}<2 \%$ ) over a relatively long $(\sim 5 \mathrm{~ms})$ period, which is a major fraction of $\tau_{E G}(10-40 \mathrm{~ms})$. As the NBI heating progresses, the $\Delta \Phi_{t}$ drop can become larger and steeper.

The $\Delta \Phi_{z}$ change of a large $\left(\delta \beta_{p \perp} / \beta_{p \perp} \sim 8 \%\right)$ event with a short drop time $\left(\tau_{i} \sim\right.$ $0.5 \mathrm{~ms}$ ) in a hydrogen plasma heated by three deuterium beams, two co-perpendicular (at 2.7.MW) and one co-tangential (at 1.3MW) beams, is shown in Fig. 2(a). The discharge parameters at $490 \mathrm{~ms}$ are: $B_{\phi 0}=-0.9 T, I_{p} \simeq 370 k A, \Phi_{p} \simeq-9.1 \mathrm{mWb}, R_{g}=1.43 \mathrm{~m}$ (geometrical center radius), $a_{\text {mid }} \simeq 0.33 \mathrm{~m}$ (plasma half-width at midplane), $\kappa \simeq 1 . \bar{\tau}$ (elongation), $\imath \simeq 0.17$ (indentation), $q_{e d g e} \simeq 4.2$ (edge safety factor), $\left\langle\beta_{\mathrm{r}}\right\rangle=3.0 \%$ (volumeaveraged toioidal $\beta$ ), and $\beta_{p \perp} \simeq 1.0$. The $\mathrm{CX}$ (charge exchange) analyzer, ${ }^{12}$ which intercepts fast neutrals escaping radially outward from the plasma at a near perpendicular angle (in direction counter to $I_{p}$ ) in the horizontal midplane, registers no large change in its mean level before and after the internal disruption (Fig. 2(c)), indicating the absence of any significant change in the fast ion loss in this direction at the sawtooth crash. The signal from the CX analyzer which detects fast neutrals that are lost co-tangentiaily (Fig. 2(d)) in the horizontal midplane exhibits a large, but short burst just after the sawtooth crash. The neutron emission falls a total of about $20 \%$ after the crash, but the decline in emission coincident with the CX burst is small (Fig. 2(b)). From these observations we infer that the fast jon loss is probably small in this event and that the drop in $\Delta \Phi_{t}$ represents, for the most part, the loss of energy from thermal ions (rather than the loss of beam ions). The decrease in the neutron emission is probably caused. in part, by a stronger slowing-down process due to the lowered central $T_{e}$ and the fast ion transport into a region of lower $T_{e}$, and, in part, by a lower emission rate due to the fast ion transport to the lower deuterium density region. In other discharges a large drop 
in the central ion temperature and toroidal ratation speed due to the sawtooth internal disruption ${ }^{33}$ has been detected by charge exchange recombination spectroscopy and $\mathrm{CX}$ analysis. The central $T_{e}$ typically drops by $15 \%$ due to the sawtooth. Important to note here is the fact that the steep drop in perpendicular energy is arrested within a short time. perhaps suggesting that unfavorable conditions causing the drop have been "healed": $\tau_{d}$ is then also the healing time constant. Some sawteet hound in PBX are unusual in terms of either the large size, the rapidity, or both, of the energy loss. They will be simply referred to as the 'large-loss' sawteeth. They may be different from the so-called giant sawteeth" that cause mostly redistribution of a large amount of energy within the plasma.

The precursor activity and the location of the inversion radius have been investigated using SXR cameras in an attempt to differentiate between sawteeth with a large. fast energy loss and normal sawteeth with a small, gradual loss. Figure 3 (a) illustrates the internal fluctuations before. large-loss sawtooth $\left(\delta \beta_{p \perp} / \beta_{p \perp} \simeq 4 \%\right.$ and $\left.r_{d} \simeq 0.5 \mathrm{~ms}\right)$ in a hydrogen discharge heated $\mathrm{jy}$ two co-perpendicular deuterium beams at about $2.6 \mathrm{WW}$. The discharge parameters are: $B_{\infty 0} \simeq-1.0 T, I_{p} \simeq 330 \mathrm{kA}, R_{g} \simeq 1.44 \mathrm{~m}, a_{\mathrm{mrd}} \simeq 0.29 \mathrm{~m}$, $\kappa \simeq 1.8,1 \simeq 0.16, q_{\text {edge }} \simeq 4.5,\left\langle\beta_{t}\right\rangle \simeq 2 \%$, and $\beta_{p \perp} \simeq 0.8$. The abscissa of Fig. $3(\mathrm{~b})$ is the horizontal radius of the flux surface tangent to each line of sight, deduced from an MHD equilibrium. Note the abrupt fall in the amplitude between 12 and $15 \mathrm{cr}$. presumably corresponding to the $q=1$ radius where the $m=1$ component falls rapidly. The phase plot in Fig. 3(c) shows the mode to be $m=1$ in the core. The phase changes outside $q=1$ indicate coupling to other helicities, as suggest ed by the nonzero fluct uation amplitude in this region. Normal sawteeth on PBX have the inversion point $\left(r_{3 n v}\right)$ close to the peak in perturbation amplitude whereas all large-loss sawteeth examined have $r_{\text {inu }}$ significantly outside the $q=1$ surface and $r_{\text {inv }}$ is often very large (typically $60 \%$. but ranging up to ia\% of $a_{\text {nid }}$. Comparing moc'e structures for successive normal and large-loss sawteeth reveals little if any difference: both have $m=1$ peaks in the same place and both show coupling to the outer regions. There are also intermediate cases in which the sawtcoth has $r_{\text {inu }}$ considerably greater than the $q=1$ radius, but show no significant energy loss. Thus, while all large-loss sawteeth have $r_{\text {inv }}$ much greater than the $q=1$ radius, not all events with $r_{\text {inv }}$ greater than the $q=1$ radius result in the rapid global energy loss. Comparison of the large-loss and intermedjate events again reveals no $\mathrm{m}$; or change in mode structure, but $r_{\mathrm{m} w}$ and the mode amplitude are larger still for the large-loss sawteeth. The data thus show no clear signature of the precursor peculiar to the large-loss sawtooth. It is also found that $r_{i n v}$ cari vary substantially in successive sawteeth.

The large-loss sawieeth are often observed in the regime, qedge $<5$ and $\beta_{p_{-}}<1.2$. In a typical discharge a series of large $\left(\delta \beta_{p \perp} / \beta_{p \perp} \sim 8 \%\right)$, fast $\left(r_{d} \sim 0.5 \mathrm{~ms}\right)$ drops may occur at intervals comparable to $\tau_{E G}(10-40 \mathrm{~ms})$. In geteral, however, the large-loss 
sawteeth can have widely varying magnitudes and drop times during a period when most macroscopic discharge parameters are steady. and can also occur as isolated events among normal sawteeth. This may indicate that their occurrence and effects on the confinement depend on the details of the equilibrium (e.g., local gradient of the current or temperature profile). The magnitude and the drop time of the sawteeth taken from many discharges vary over the range: $0.02<\delta \Phi_{t}\left(m_{t} W b\right)<1.5$ and $0.3<\tau_{d}(m s)<6$. or in normalized forms, $3 \cdot 10^{-3}<\delta \beta_{p \downarrow} / \beta_{p \perp}<0.2$ and $10^{-2}<\tau_{d} / \tau_{E G}<0.4$. The energy confinement degradation defined by Eq. (1). in which the average rate of change. $\delta \Phi_{t} / \tau_{d}$, is used instead of inst ant aneous $\Delta \dot{\Phi}_{\ell}$, is plot ted against the total heating power in Fig. 4. The maximum degradation at each power level (dashed line) that can be tolerated without causing a disruption increases with the heating power. However. at each power level, degradation of all degrees is observed. The most severe events can cause a very large energy loss $\left(0.2 \leq \delta \beta_{p \perp} / \beta_{p \perp}<1.0\right)$ over a short period $\left(\tau_{d}<3 \mathrm{~ms}\right)$. affect the current significantly $\left(\delta I_{p} / I_{p}>2 \%\right)$, and can lead to a minor disruption or to a complete termination of the discharge with only a short delay period. These events are not included in Fig. 4.

In summary, we have shown that the energy expelled from the core by a sawtooth internal disruption in NBI-heated, bean-shaped plasmas in PBX can be rapidly transported through the outer region and lost from the plasma, indicating a momentary loss of confinement. We have $\equiv$ lso shown that the sawtooth events in the bean-shaped PBX plasmas often have unusually large inversion radius. Rapid energy loss after each sawtooth crash would affect the initial conditions of each cycle of sawtooth oscillations in fusion plasma modeling. We may speculate on several possible explanations for the rapid transport. Nonlinear enhancement of the transport ${ }^{8}$ caused by a massive energy input from a large-volume core into the sm all-volume outer region, and generation of turbulence ${ }^{4}$ both in the core and outer regions are possible mecharisms. A picture based upon the stochastic field generated through mode coupling ${ }^{14}$ across the plasma cross section immediately after the internal disruption and subsequent rapid recovery of good magnetic surfaces could qualitatively explain some features of the momentary confinement degradation and 'healing.' The unusually large inversion radius could be consistent with a picture of a global instability where tine interaction between rational q surfaces increases rapidly at some mode amplitude that depends on the fine scale details of the equilibrium.

The PBX project is supported by the U.S. Department of Ener gy under Contract No. DE-AC02-76-CHO-3073. 


\section{References}

'S. von Goeler. et al.. Phys. Rev, Lett. 33, 1201 (19i4),

${ }^{2}$ A.W. Edwards, et al., Phys. Rev. Lett, 57, 210 (1986).

${ }^{3} \mathrm{~K}$. McGuire. et al. in 12th European Conference on Controlled Fusion and Plasma Physics, Budapest, September 1985, edited by L. Pócs and A. Mont vai (European Physical Society, Budapest, 1985), Vol. 9F, Part-I, p.134; D. J. Campbell, et. al., ibid. p. 130.

“M.A. Dubois, et al., Nuclear Fusion 23, $14 i$ (1983).

${ }^{5}$ J.A. Wesson. Plasma Phys. Cont. Fusion 28, 242 (1986); R.E. Denton. et al., Phys. Rev. Lett. 56, 24JT (1986).

${ }^{6}$ B.B. Kadomtsev, Fizika Plazmy 1, 710 (1975) [Soviet J. Plasma Phys. 1, 389 (1975)].

'W. Pfeiffer, et al., Nuciear Fusion 25, 655 (1985).

${ }^{8}$ G. Bateman, Princeton Plasma Physics Lab. Rep. PPPL-2373 (1986); L. Sugiyama. MIT Rep. PTP-84/2 (1984).

9.D. Strachan, private communication; and see also section on fast icn disruptions, p.11. Annual Report. October 1 - Sept. 30, 1980, Princeton Plasrna Physics Lab. Rep. PPPL-Q-38 (1981); E.D. Fredrickscn, et al., Nucl. Fusion 26, 849 (1986); R.J. Goldston. et al., Princeton Plasma Physics Lab. Rep. PPPL-2359 (1986).

${ }^{10}$ K. Bol, et al., Princeton Plasma Physics Lab. Rep. PPPL-2327 (1986).

${ }^{11}$ V.D. Shafranox, Plasma Physics, 13, 757 (1971).

${ }^{12}$ R. Kaita, et al., invited paper, 13th Europ. Conf. on Cont. Fusion and Plasma Physics. Schliersee, FRG, April, 1986.

${ }^{13}$ G. Ganmel, et al., Princeton Plasma Physics Lab. Rep, PPPL-2340 (1986).

${ }^{14}$ R. Izzo, et al., Princeton Plasma Physics Lab. Rep. PPPL-2342 (1986). 


\section{Figures}

FIG. 1. The evolution of (a) $I_{F}$ (b) the displaced toroidal fiux. $\Delta \Phi_{t}$, and (c) central chord SXR in an NBI-heated bean-shaped plasma.

FIG. 2. The evolution of (a) $\Delta \Phi_{t}$, (b) neut ron flux. (c) fast neut ral flux at $35 k \in V$ escaping from the plasma in a counter-perpendicular direction, and (d) fast neutral flux at $35 \mathrm{keV}$ escaping from the plasma in a co-tangential direction, all through a large sawtooth internal disruption. The drop period, $\tau_{d}$, is defined as the time required to complete $90 \%$ of the total sawtooth $\Delta \Phi_{t}$ drop, $\delta \Phi_{t}$ (see (a)).

FIG. 3. (a) Waveform from an SXR detector viewing $6 \mathrm{~cm}$ off axis; (b) relative fuctuation amplitude $(f=6.1 \mathrm{kHz})$ as a funcition of flux surface radius. The $q=1$ surface lies within the shaded areas and the arrows indicate the inversion point of crash; (c) Phase plot as a function of flux surface radius.

FIG. 4. The ratio of the global to instantaneous confinement time, $\tau_{E G} / \tau_{E}$ (Eq. 1), is plotted against the total heating power. 
\# $86 \times 1283$

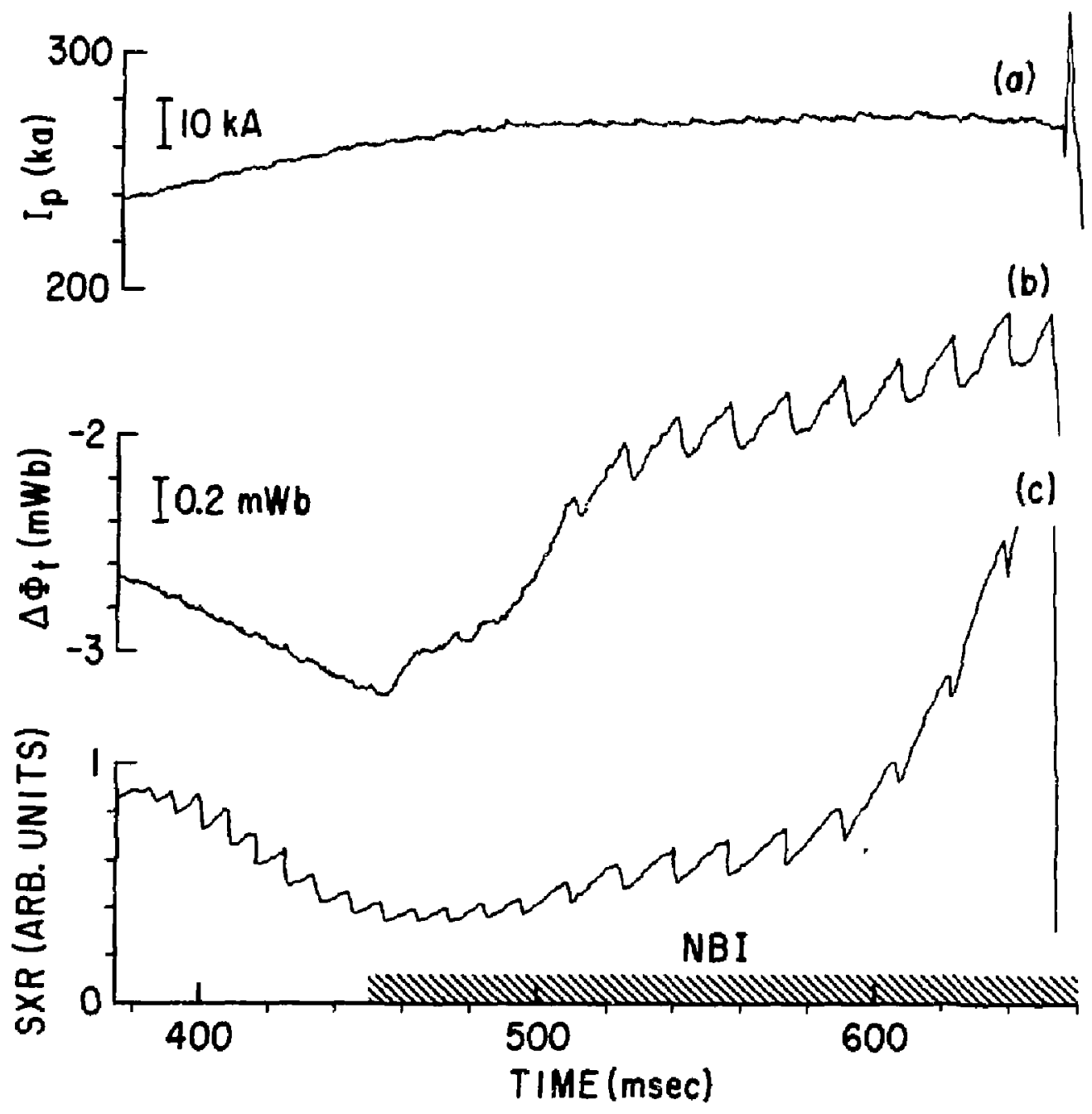

Fig. 1 

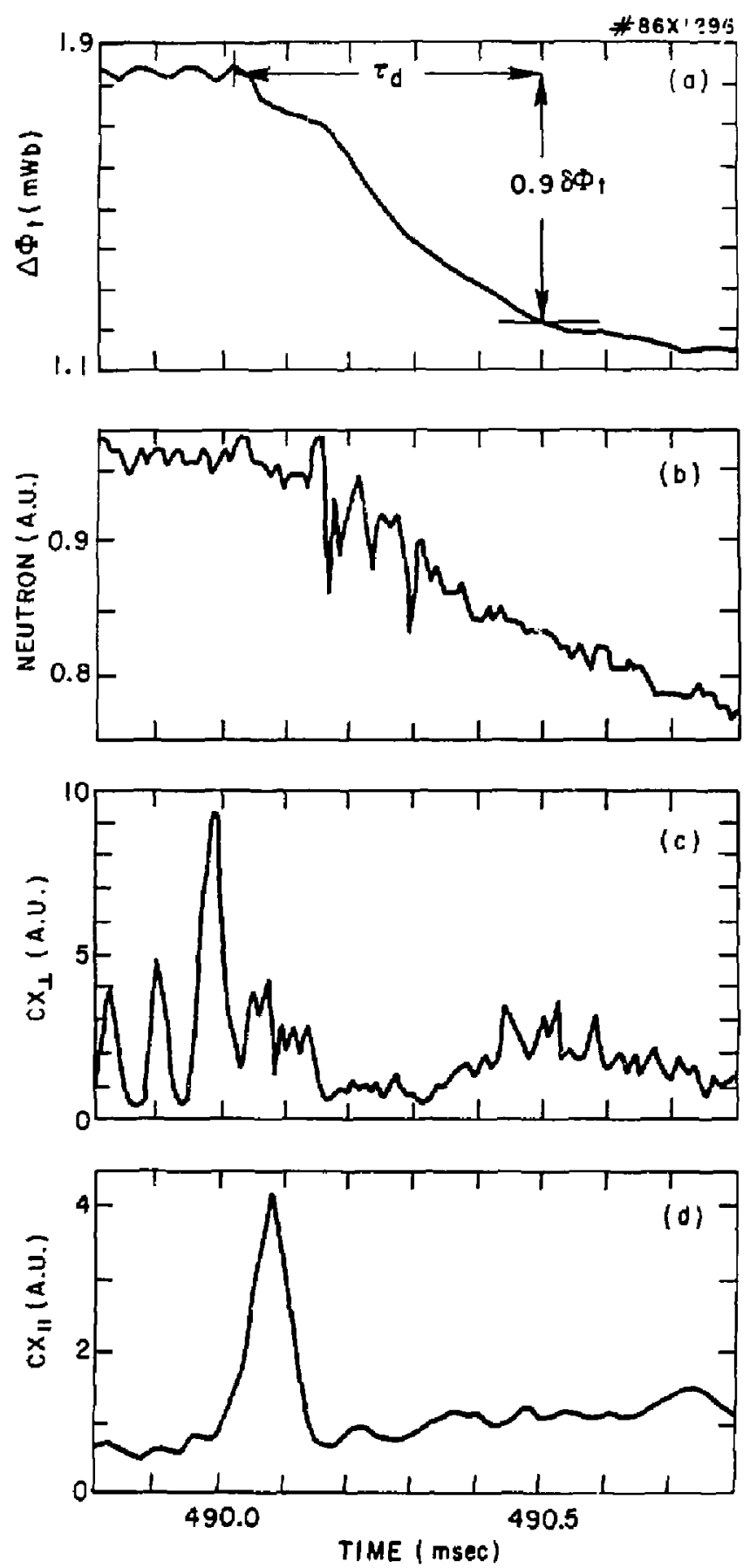

Fig. 2 
\#86 X1295
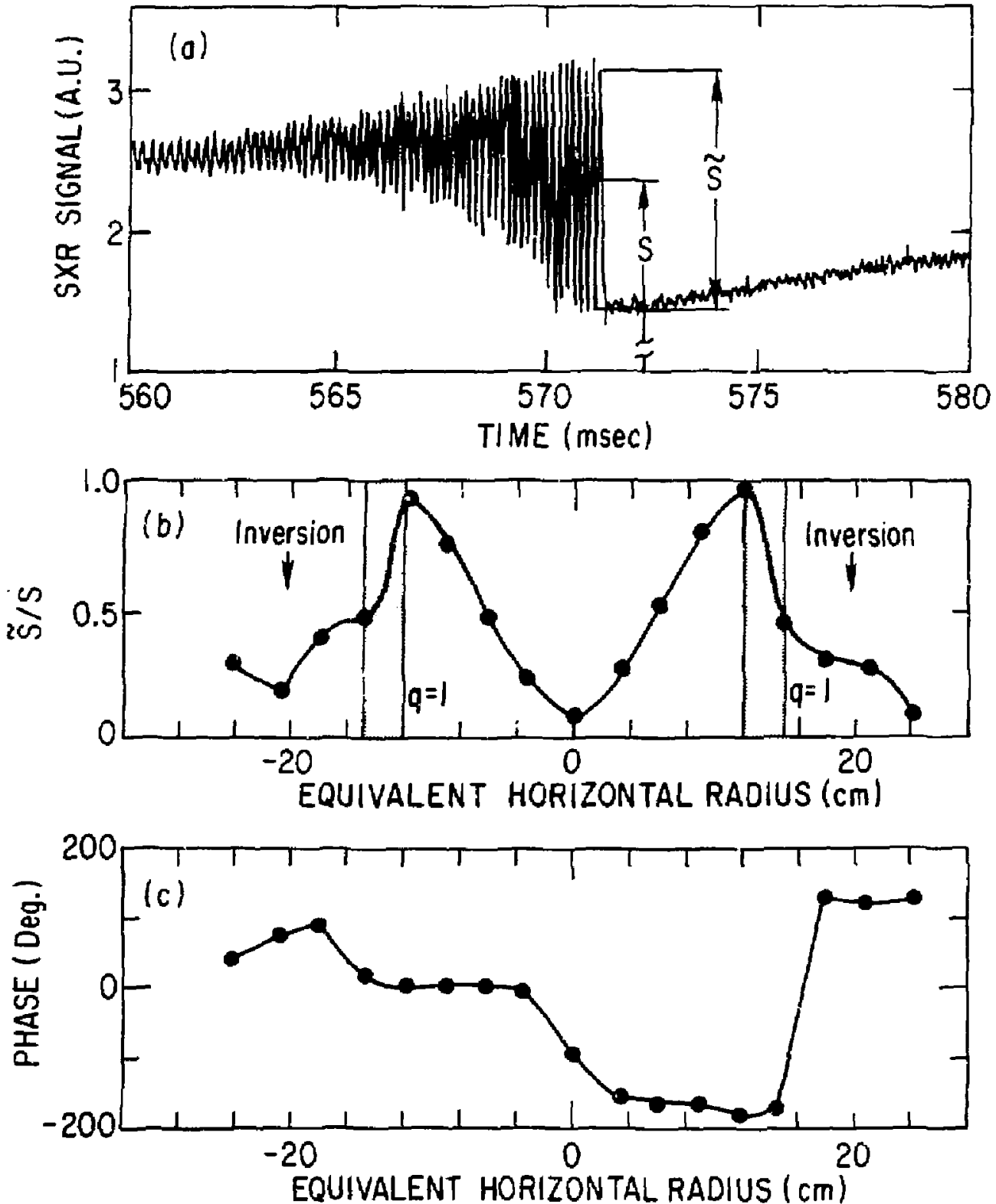

Fig. 3 


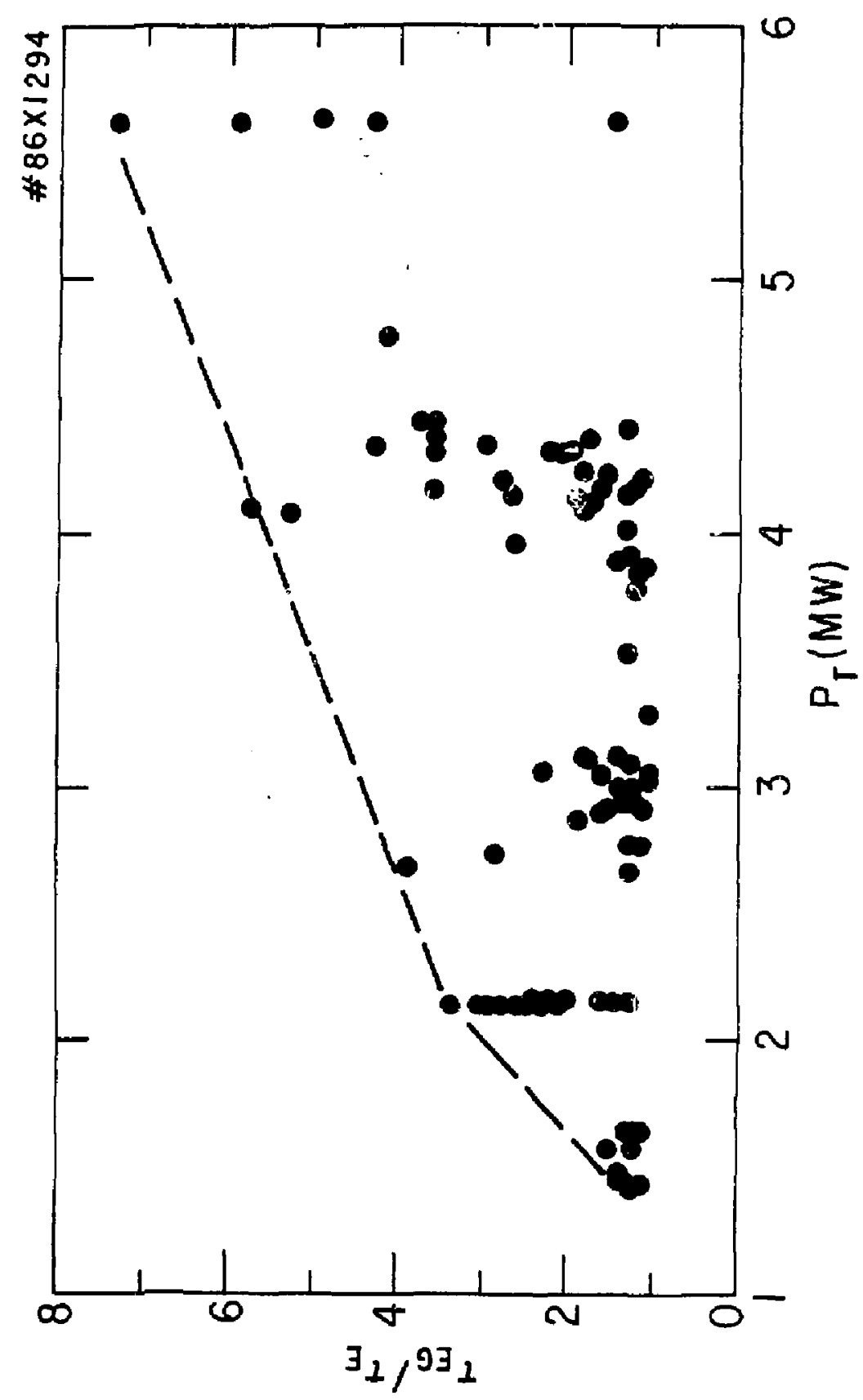


Plasmo Res Lab, Austra Nat'l Unly, AuSTRALIA

Or. Frank J, Poolont, unls ot Woliongong, AUSTRALIA

Prof. 1.R. Jones, FIInders Univ., AUSTRALIA

Prof. M.H. Brennan, UnIr Sydhoy, AUSTRALIA

Prot, F. Cap, Inst Theo Phys, AUSTRIA

M. Goossans, Astronomiseh Instituut, BELGIIM

Prot, R. Bouciqua, Laberatorlum voor Natuurkunde, BELGIUM

Dr. D. Palumba, Dg xll fuslon Prog, aELGiLM

Ecole Royale MIIlitalre, Lab de Phys Plasmas, BELGIUM

Dr. P.H. Sakanake, Univ Estadual, BRRIL

LIb. \& Doe, Dive., Instituto de Posquisos Especlolo, BRNZIL

Dr. C,R. Jemes, UnIV of Alborta, CANADA

Prof. J. Tolchmann, Unlv af Montreal, CANADA

Dr. H.M. Skarsgard, UnIr of Saskatchewan, Canmoa

Prot. S.R. Sroenlvasan, University of Colgary, CANADA

Prof. Tudor W. Johnston, INPS-Energla, CANADA

Dr. Hannes Barnard, Univ Britisn Columbla, CANADA

Dr. M.P. Bochynski, MPB Technologies, InC., CANADA

Chelk Rivor. Nucl Lab, CANADA

Znengwe LI, SW Inst Physles, CHINA

LIbrary, Tsing Huo Unlversity. CHINA

Librarian, institute of Physles, CHINA

Inst Plosms Phys, Acadenle SInleo, CHINA

Dr. Petor Lukac, Komenskeho Unly, CZECHOSLOVAKIA

The Librartan, Culhan Laboratory, ENGLANn

Prof. Schatzman, Observatoire do NICa, FRANCE

J. Radet, CEN-BP6, FRAKCE

JET Ruading Room, JET Joint Undertaking, ENGLIND

AH Dupas Library, NH Dupas LIbrary, FRAtKE

Dr. Tom Mual, Acadony Blbllographle, HOWG KONG

Preprlnt Library, Cent Res Inst Fhys, HuHGaRY

Dr. R.K. Chhajlanl, VIkram Inlv. INOIA

Dr. B. Dasgupta, Saha Inst, InO/A

Or. P. Kan, Ohystcal Rasearch Lab, INOIA

Dr. Phllllo Rosenaw, Israel Inst Tech, ISRAEL

Prof. 5. Cuparman, Tol Aviv UnIversIty, ISRAEL

Prof, G, RastagnI, UnIv DI Padova, ITALY

Librarian, Int'l Ctr Theo Phys, ITALY

MIss Clofle De Palo, AssOC EURATOM-ENEA, ITALY

BIbIloteca, del CNR ELPATOA, ITALY

Dr. H. Yanato, Tosnlbe Res a Dev, JAPAN

Direc. Dopt. Lg. TokBmak Duv. JAERI, JAPAN

Prof. Nobuyukl inoue, University of Tokyo, JAPAN

Reseoren Info Conter, Nagoyo Unlversity, JAPAN

Prot. KYoJl Nisnikemo, UnIV of HIroshImo, JAPAN

Prof. SIgerJ Mor 1, JAERI, JAPAN

Prot. S. Tonaka, Kyoto UnIversIty, JAPAN

Library, Kyoto Unlversity, JAPAN

Prof. Ichiro Kawakanl, NIhon UnIv, JAPAN

Prof. Satoshl Itoh, Kyushu University, JAPAN

Dr. D.1, Chol, Adv, Inst Sel \& Teen, KOREA

Tech Info Dirislon, KAERI, KOAEA al bllothesk, Fom-Inst Voor PIosma, METHERLANDS

Prof. a,5. Llloy, University of Waikato, NEW ZEALANO Prof. J.A.C. Cabral, Inst Suporlor Tecn, PORTJGAL

Dr. Octorjan Patrus, ALI CLZA Unluarsity, ROMANIA

Prof. M, A. Hollsorg, Unlvarsity of Natbl, SO A.FRICA

Or. Johan de Villiers, Plasme Physics, Nucor, SO AFRIizA

Fusion DIV. LIbrary, JEN, SPAIN

Prof, Hans WIlhalmson, Chalmers Unly Tach, SwEDEN

Dr. Lennart Stantlo, Unlyarsity of UMEA, SWEDEN

LIbrary, Royal Inst Toch, SWEDEN

Centre de Recherchesen, Ecole Polytech Fed, SwITERLAND

Dr, V,T. Tolok, Kharkay Phys Tuen Ins, USSR

Dr. O.D. Ryutov, S! berlan Acad Sel, USSR

Dr. G.A. El liseov, Kurchator Instltute, USSR

Dr. V.A. Glukhikh, Inst Electrothyslcai, USSR

Instltuto Gen. Physics, USSR

Prot. T.J.M. Boyd, UnIV Collego $N$ Holas, HALES

Dr. K. Sehlndior, Rughr Unlversltat, W. GERMANY

ASDEX Reeding Rm, IPP Max-Planck-Institut fü

Plasmaphysik, F,R,G.

Nuclear Riss Estab, Julleh Ltd, W. GERMANY

LIbrorlan, Maxflanck Institut, W. GEAMANY

alblicthek, Inst Plasmaforschung, W. GERMANY

Prof, R,K. Janev, Inst Phys, Yugoslavia 